\title{
An investigation into the dynamics of partial discharge propagation in mineral oil based nanofluids
}

\author{
Huifei Jin, Peter H.F. Morshuis, Armando Rodrigo Mor \\ Electrical Sustainable Energy \\ Delft University of Technology \\ Delft, the Netherlands \\ H.Jin@tudelft.nl
}

\author{
Thomas Andritsch \\ Electronics and Computer Science \\ University of Southampton \\ Southampton, United Kingdom
}

\begin{abstract}
Recent studies present a model which assumes that conductive nanoparticles can reduce the speed of the positive streamer propagation in mineral oil due to electron trapping at the particle surface. Time resolved partial discharge measurements can be used to evaluate the discharge dynamics and to verify this hypothesis. A special measurement setup was built to enable the recording of the discharge dynamics. In this study, the effect of nanoparticles with different conductivities on the discharge dynamics of mineral oil is investigated. The time resolved current shapes of partial discharges in nanofluids and mineral oil are compared. To understand the effect of the conductivity of the nanoparticles on the partial discharge dynamics of mineral oil, nanoparticles with two different conductivities are synthesized with mineral oil. The two types of nanoparticles are silica and fullerene. The host fluid used in this study is Shell DialaS3ZXIG mineral oil.
\end{abstract}

Keywords—nanofluid; partial discharge; mineral oil; silica; fullerene

\section{INTRODUCTION}

Mineral oil is the lifeblood of the modern power grid. As one of the main insulating media of transformers mineral oil performs two functions: preventing electric current between conducting elements and transferring the heat generated by active parts (winding and magnetic core) to the tank wall [1]. In recent years, much effort has been devoted to effectively improving the dielectric strength and heat transfer properties of mineral oil. Great progress has been made in improving the electrical breakdown strength and heat transfer of mineral oils by using nanoparticles as the modifying agent [2-12].

The term "nanofluids" was introduced by researchers at the Argonne National Laboratory and refers to a two-phase mixture containing a liquid phase which is the host, and dispersed nanoparticles in suspension. Regarding the research on the electrical properties of nanofluids, several publications have shown an increased breakdown strength of oil by introducing magnetite and titania nanoparticles [13-17]. To explain the mechanism behind the enhanced breakdown strength of nanofluids, recent studies introduced a model which assumes that conductive nanoparticles can reduce the speed of positive streamer propagation in mineral oil due to electron trapping at the particles surface [18-20]. O' Sullivan et al. suggested that the charge relaxation time constant of the nanoparticle may have a major bearing on the extent to which the electrodynamics process in the liquid are modified [18]. If the nanoparticles' relaxation time constant is short relative to the timescales of interest for streamer growth, their presence in the oil may significantly modify the electrodynamics. On the other hand, if the nanoparticles' relaxation time constant is long, relative to the timescales involved in streamer growth, their presence will have little effect upon the electrodynamics. The charge relaxation constant can be calculated by the relative permittivities and conductivities of the host fluid and nanoparticles.

In this study, a special partial discharge measurement setup was built to verify the hypothesis mentioned above. This time resolved partial discharge measurement can be used to record the discharge dynamics. The goal of this study is to investigate the effect of nanoparticles with different conductivities on the discharge dynamics of mineral oil under DC voltage.

\section{SAMPLES}

\section{A. Materials}

The base fluid in this study is Shell Diala S3ZXIG mineral oil, which is widely used in HV transformers and generators. The nano-fillers in this study are silica and fullerene nanoparticles. The silica nanoparticles were purchased from Sigma-Aldrich. The average particles size is $15 \mathrm{~nm}$ according to the data sheet. The fullerene $\mathrm{C}_{60}$ nanoparticles were purchased from SES research, USA. The molecular size of fullerene $\mathrm{C}_{60}$ is $6.83 \AA$ and agglomeration size in dispersion is around $70 \mathrm{~nm}$. The reason for choosing these two types of nanoparticles is that the conductivities of silica and fullerene are different. Table I shows the conductivities, relative permittivities and the charge relaxation time of silica and fullerene nanoparticles in mineral oil. The relative permittivities of silica and fullerene are similar according to the data sheet. The difference of the charge relaxation time constant between the two types of nanoparticles is mainly caused by the different conductivities. It can be seen that the charge relaxation time constant for fullerene is much shorter than that for silica.

TABLE I. CONDUCTIVITIES, RELATIVE PERMITTIVITIES AND CHARGE RELAXATION TIME CONSTANT OF SILICA AND FULLERENE

\begin{tabular}{|l|c|c|}
\hline \multicolumn{1}{|c|}{ Properties } & Silica & Fullerene \\
\hline Conductivity [S/m] & $10^{-16}$ to $10^{-12}$ & $9.86 \times 10^{-4}$ \\
\hline Relative permittivity & 3.8 to 5.4 & 4.0 to 4.5 \\
\hline Charge relaxation time constant & 24.5 to $36.7 \mathrm{~s}$ & 75 to $80 \mathrm{~ns}$ \\
\hline
\end{tabular}




\section{B. Nanofluids preparation}

The particles in all nanofluids samples were dispersed by means of ultrasonication. First, the nanoparticles were weighed under a fume-hood. Second, the nanoparticles were mixed with mineral oil with a magnetic stirrer for 30 minutes. The last step was breaking the clusters in the nanoparticlemineral oil mixture with an ultrasonic bath for 2 hours. The mass fraction for both silica and fullerene nanofluids is $0.01 \%$.

\section{PARTIAL Discharge MEASUREMENTS}

\section{A. Measurement Set-up}

To record the "true" discharge current, as little as possible affected by the external circuit, a time-resolved experimental set-up was designed with the proper attention for minimizing inductances. The basic circuit of partial discharge measurement for this study is shown in Fig.1. Measuring discharges is based on the measurement of a charge displacement that causes a current in the leads to a sample. This is performed by placing an impedance $\mathrm{Z}$ in the circuit. In this way the external charge displacement is measured. In the basic circuit, the coupling capacitor $\mathrm{K}$ provides a closed circuit for the discharge current.

Fig.2 shows the experimental set-up for time-resolved partial discharge measurement. Capacitor $\mathrm{F}$ is connected with the high voltage DC source in parallel to short circuit high voltage noise from the $40 \mathrm{kV}$ DC source. The resistor $\mathrm{R}$ is connected with the high voltage DC source and test electrode in series. The electrode is connected in series with impedance $Z$. The current shape of the partial discharge is displayed on an oscilloscope.

Fig. 3 shows a detailed view of the need-plane electrode configuration. The radius of curvature of the needle tip is 1 $\mu \mathrm{m}$. The plane electrode consists of a $28 \mathrm{~mm}$ diameter measuring electrode and a concentric $180 \mathrm{~mm}$ diameter guard electrode. The gap distance is $20 \mathrm{~mm}$. The needle electrode holder and guard electrode act as coupling capacitor $\mathrm{K}$. The guard electrode is connected to the ground. The measuring electrode is connected with measuring impedance $Z$. Impedance $\mathrm{Z}$ consists of six resistors of $300 \mathrm{Ohm}$ in parallel to achieve 50 Ohm measuring impedance. This is shown on the back side of the plane electrode. The discharge signal is fed via a 50 Ohm transmission line to the oscilloscope.

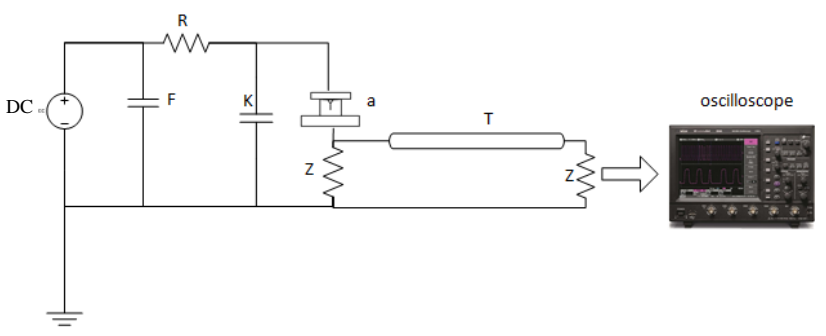

Fig. 1. Basic circuit for partial discharge measurement (a: test sample; k: coupling capacitor; Z: measuring impedance; $\mathrm{T}$ : transmission line with impedance Z; F: capacitor for short circuiting high frequency noise from the DC source; R: resistor for limiting the current)

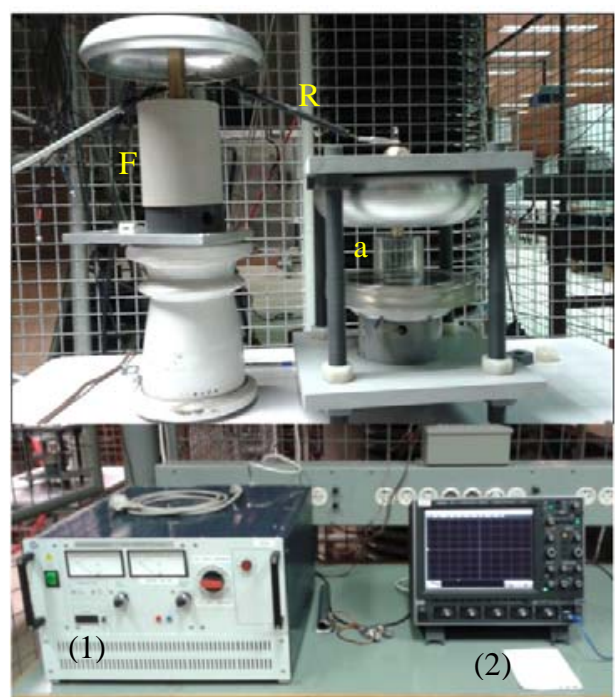

Fig. 2. Experimental set-up for time-resolved partial discharge (F: capacitor for shorting out high frequency noise from the DC source; R: resistor for limiting the current; a: test sample with needle-plane electrode; (1) high voltage DC source; (2) oscilloscope)

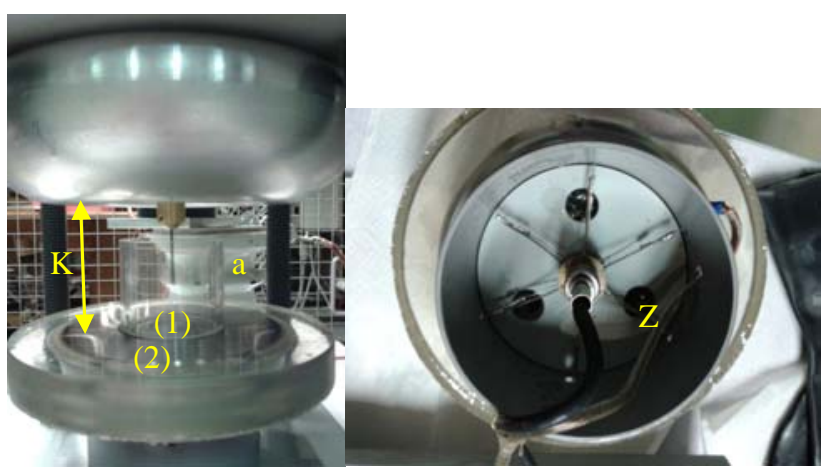

(a)

(b)

Fig. 3. Detailed view of needle-plane electrode; (a) front side view ((1) measuring electrode, connected to the measuring impedance Z; (2) concentric guard electrode; K: the electrode holder and guard electrode act as coupling capacitor; a: test sample container with needle-plane electrode); (b) back side view of plane electrode (Z: 50 Ohm measuring impedance, consists of six 300 Ohm resistors in parallel)

\section{B. Measurement results}

For the partial discharge measurements, five samples were prepared for each nanofluid. For each sample, 10 tests were performed.

The quantities which are used for comparing the partial discharge phenomena for mineral oil, $0.01 \%$ silica and fullerene nanofluids are: inception voltage, wave shape, discharge magnitude and partial discharge voltage amplitude

1) Inception voltage

The voltage rise is controlled by hand, with a rate of rise around $1 \mathrm{kV} / \mathrm{s}$. The results of the measurements of the partial 
discharge inception voltage of mineral, $0.01 \%$ silica and fullerene nanofluids are shown in Fig.4. The blue color represents mineral oil, red represents the silica nanofluid and yellow represents the fullerene nanofluid. It can be seen that the inception voltage of silica nanofluid is about $20 \%$ higher than that of mineral oil, while the difference of the inception voltage of the fullerene nanofluid is about $10 \%$ higher than that of mineral oil.

\section{2) Discharge magnitude}

The discharge magnitude is calculated by integrating the time duration and current amplitude of all the discharge pulses in one partial discharge sequence. The results of the discharge magnitude of mineral oil, silica and fullerene nanofluids were analyzed with Weibull software. Fig.5. shows the 2-parameter Weibull distribution of the discharge magnitude of the three fluids. Blue circles represent the discharge magnitude for mineral oil. Red triangles show the value for silica nanofluids. Yellow squares represent the value for fullerene nanofluid. The discharge magnitude of mineral oil decreased more than half by introducing $0.01 \%$ silica nanoparticles. The reduction due to fullerene nanoparticles is also significant, but smaller than for silica nanoparticles. Table II shows the mean value and $62.3 \%$ value of discharge magnitude for the three fluids. The reductions of the mean discharge magnitude of mineral oil are $60 \%$ by introducing silica nanoparticles and $36 \%$ by introducing fullerene nanoparticles.

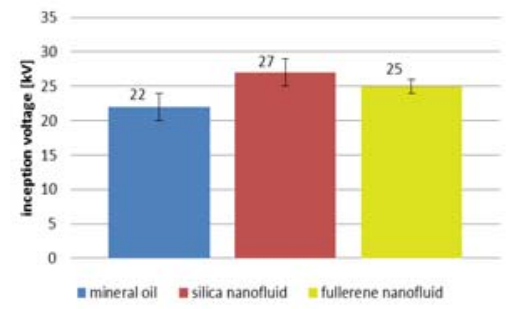

Fig. 4. Inception voltage of mineral oil, $0.01 \%$ silica and fullerene nanofluids

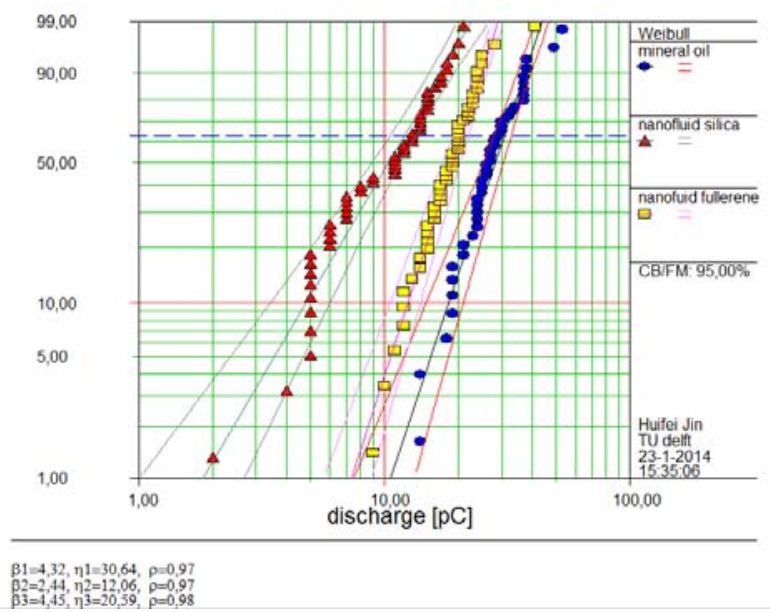

Fig. 5. 2-parameter Weibull distribution of the dishcarge magnitude in mineral oil, silica and fullerene nanofluids
TABLE II. MEAN VALUE AND 63.2\% POPULATION VALUE OF DISCHARGE MAGNITUDES OF MINERAL OIL, SILICA AND FULLERENE NANOFLUIDS

\begin{tabular}{|c|c|c|c|c|c|c|}
\hline fluids & $\begin{array}{c}\text { Mean } \\
\text { value } \\
{[\mathbf{p C}]}\end{array}$ & $\begin{array}{c}\boldsymbol{\sigma} \\
{[\mathbf{P C}]}\end{array}$ & reduction & $\begin{array}{c}\mathbf{6 3 . 2 \%} \\
\mathbf{v a l u e} \\
{[\mathbf{p C}]}\end{array}$ & $\begin{array}{c}\boldsymbol{\sigma} \\
{[\mathbf{p C}]}\end{array}$ & reduction \\
\hline $\begin{array}{c}\text { Mineral } \\
\text { oil }\end{array}$ & 28 & 2 & -- & 31 & 2.5 & -- \\
\hline $\begin{array}{c}\text { silica } \\
\text { nanofluid }\end{array}$ & 11 & 1.5 & $60 \%$ & 12 & 1.5 & $40 \%$ \\
\hline $\begin{array}{c}\text { fullerene } \\
\text { nanofluid }\end{array}$ & 18 & 1 & $36 \%$ & 21 & 1.5 & $32 \%$ \\
\hline
\end{tabular}

\section{3) Partial discharge voltage amplitude}

The peak partial discharge voltage amplitudes of a single pulse in mineral oil, silica and fullerene nanofluids are compared. The 3-parameter Weibull distribution of the voltage amplitude is shown in Fig. 6. For a clear view, only the data before adding the location parameter is shown in Fig.6. It can be seen that the voltage amplitude for silica is smaller than that for mineral oil. The voltage amplitudes for fullerene and mineral oil are similar. Table III shows the mean value and 62.3 value of voltage amplitude for the three fluids. By introducing $0.01 \%$ silica nanoparticles, the voltage amplitude is reduced by $16 \%$. After adding $0.01 \%$ fullerene nanoparticles, the reduction is only $4 \%$.

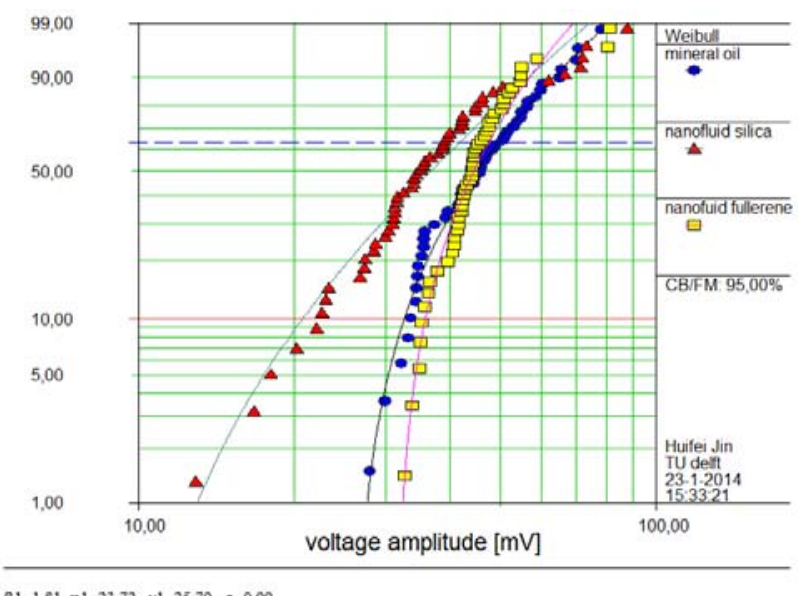

$\beta 1=1,81, \eta 1=23,72, \eta 1=25,79, \rho-0,99$

$\beta 2=2,21, \eta 2=32,79, \quad, 2=890, \rho=098$

Fig. 6. 3-parameter Weibull distribution of the PD voltage amplitudes in mineral oil, silica and fullerene nanofluids

TABLE III. MEAN VALUE AND 63.2\% POPULATION VALUE OF PD VOLLTAGE AMPLITUDES OF MINERAL OIL, SILICA AND FULLERENE NANOFLUIDS

\begin{tabular}{|c|c|c|c|c|c|c|}
\hline Fluids & $\begin{array}{c}\text { Mean } \\
\text { value } \\
{[\mathbf{m V}]}\end{array}$ & $\begin{array}{c}\boldsymbol{\sigma} \\
{[\mathbf{m V}]}\end{array}$ & reduction & $\begin{array}{c}\mathbf{6 3 . 2 \%} \\
\text { value } \\
{[\mathbf{m V}]}\end{array}$ & $\begin{array}{c}\boldsymbol{\sigma} \\
{[\mathbf{m V}]}\end{array}$ & reduction \\
\hline $\begin{array}{c}\text { Mineral } \\
\text { oil }\end{array}$ & 47 & 3 & -- & 50 & 4 & -- \\
\hline $\begin{array}{c}\text { silica } \\
\text { nanofluid }\end{array}$ & 38 & 2 & $16 \%$ & 43 & 5 & $14 \%$ \\
\hline $\begin{array}{c}\text { fullerene } \\
\text { nanofluid }\end{array}$ & 45 & 3 & $4 \%$ & 47 & 3 & $6 \%$ \\
\hline
\end{tabular}




\section{DISCUSSION}

It was mentioned in the introduction that recent studies suggested that conductive nanoparticles can reduce the speed of positive streamer propagation in mineral oil due to electron trapping at the particle surface [18-20]. In contrast to what would be expected based upon the above assumptions, silica particles show a larger influence on the partial discharge dynamics of mineral oil than fullerene particles.

The reason for this still needs to be investigated. Because the surface of fullerene is hydrophobic and that of silica is hydrophilic, a possible explanation is that the hydrophilic surface of silica adsorbs water. This can reduce the influence of moisture content on the partial discharge dynamics of mineral oil. However, fullerene and silica are different nanoparticles, hence the results can be confirmed by comparing the partial discharge results of untreated hydrophilic silica nanofluid with surface modified hydrophobic silica nanofluid. In the next stage, this hypothesis will be tested by measuring the partial discharge dynamics in dried and degassed mineral oil and the result compared with that of undried mineral oil and $0.01 \%$ silica nanofluid.

\section{SUMMARY}

In this study, the results of partial discharge measurements in mineral oil, $0.01 \%$ silica and fullerene nanofluids are presented. The results of inception voltage, discharge magnitude, voltage amplitude the partial discharge measurements in the three fluids are compared. The results show the following:

- The inception voltage of silica nanofluid is roughly $20 \%$ higher than that of mineral oil, while the difference of the inception voltage of mineral oil and fullerene nanofluids is about $10 \%$, with the nanofluids having higher values.

- The discharge magnitudes of silica nanofluid and fullerene nanofluids are both lower than that of mineral oil. For silica nanofluid, the reduction is $60 \%$, and for fullerene nanofluid the reduction is $36 \%$.

- The voltage amplitude measured in mineral oil is reduced by $16 \%$ due to the additional silica nanoparticles and $4 \%$ due to fullerene nanoparticles.

\section{REFERENCES}

[1] K. Karsai, D. Kerenyi, L. Kiss, “ Large Power Tramsformers”, Elsevier, Amsterdam, pp. 351-359, 1987.

[2] S.U.S. Choi and J.A. Eastman, "Enhancing Thermal Conductivity of Fluids with Nanoparticles” International Mechanical Engineering Congress \& Exposition, pp.99-105, 1995.

[3] J.A. Eastman, S.U.S. Choi, L.J. Thompson and S. Lee, "Enhanced thermal conductivity through the development of nanofluids," Materials Research Society Symposium Proceedings, pp. 3-11, 1996.
[4] M. Liu, M. Lin, I. Huang and C. Wang, "Enhancement of thermal conductivity with $\mathrm{CuO}$ for nanofluids,” Chemical Engineering \& Technology , pp. 72-77, 2006.

[5] Y. Hwang, H.S.K. Par, J.K. Lee and W.H. Jung, "Thermal conductivity and lubrication characteristics of nanofluids,” Current Applied Physics, pp.67-71, 2006.

[6] W. Yu, H. Xie, L. Chen and Y. Li, "Investigation of thermal conductivity and viscosity of ethylene glycol based $\mathrm{ZnO}$ nanofluid," Thermochimica Acta, pp.92-96, 2009.

[7] H.A. Mintsa, G. Roy, C.T. Nguyen and D. Doucet, "New temperature dependent thermal conductivity data for water-based nanofluids," International Journal of Thermal Sciences, pp.363-371, 2009.

[8] S. Zeinali Heris, M. Nasr Esfahany and S.G. Etemad, "Experimental investigation of convective heat transfer of $\mathrm{Al}_{2} \mathrm{O}_{3}$ /water nanofluid in circular tube," International Journal of Heat and Fluid Flow, pp.203-210, 2007.

[9] D. Kim, Y. Kwon, Y. Cho, C. Li, S. Cheong and Y. Hwang, "Convective heat transfer characteristics of nanofluids under laminar and turbulent flow conditions," Current Applied Physics, pp.119-123, 2009.

[10] J.Y. Jung, H.S. Oh and H.Y. Kwak, "Forced convective heat transfer of nanofluids in microchannels," Internal Journal of Heat and Mass Transfer, pp.466-472, 2009.

[11] K.V. Sharma, L.S. Sundar and P.K. Sarma,. "Estimation of heat transfer coefficient and friction factor in the transition flow with low volume concentration of $\mathrm{Al}_{2} \mathrm{O}_{3}$ nanofluid flowing in a circular tube and with twisted tape insert,” International Communications in Heat and Mass Transfer, pp. 503-507, 2009.

[12] R. Saidur, K.Y. Leong and H.A. Mohammad, “A review on applications and challenges of nanofluids," Renewable and Sustainable Energy Reviews, pp. 1646-1668, 2011.

[13] V. Segal, A. Hjorsberg, A. Rabinovich, D. Nattrass and K. Raj, “AC $(60 \mathrm{~Hz})$ and impulse breakdown strength of a colloidal fluid based on transformer oil and magnetitie nanoparticles,” Electrical Insulation, pp.619-622, 1998.

[14] B. Du, J. Li, B. Wang and Z. Zhang, "Preparation and breakdown strength of $\mathrm{Fe}_{3} \mathrm{O}_{4}$ nanofluid based on transformer oil," International Conference on High Voltage Engineering and Application, pp.311-313, 2012.

[15] Y. Du, Y. Lv, J. Zhou, X. Li and C. Li, "Breakdown properties of transformer oil based $\mathrm{TiO}_{2}$ nanofluid,” Annual Report Conference on Electrical Insulation and Dielectric Phenomena, pp.1-4, 2010.

[16] D.E.A. Mansour, E.G. Atiya, R.M. Khattab and A.M. Azmy, "Effect of Tatiana Nanoparticles on the Dielectric properties of Transformer OilBased Nanofluids,” Annual Report Conference on Electrical Insulation and Dielectric Phenomena, pp. 295-298, 2012.

[17] J. Li, Z. Zhang, P. Zou and S, Grzybowsku, "Preparation of a vegetable oil-based nanofluid and investigation of its breakdown dielectric properties,” Electrical Insulation Magzine (28):5, pp.43-50, 2012.

[18] F.M. O'Sullivan, "A Model for the Initiation and Propagation of Electrical Streamers in Transformer oil and Transformer oil based nanofluids”, PhD thesis, Massachusetts Institute of Technology, 2007.

[19] J.G. Hwang, F.M. O’Sullivan, M. Zahn, O. Hjorstam, L.A.A. Petterson and R. Liu. "Modelling of streamer propagation in transforemer oil based nanofluids”, Annual Report Conference on Electrical Insulation and Dielectric Phenomena, pp. 361-366, 2008.

[20] J.G. Hwang, F. O’Sullivan, M. Zahn, O. Hjorstam, L.A.A. Petterson and R. Liu. "Electron scanvenging by conductive nanoparticles in oil insulated power transformer”, Electrostatics Joint Conference Proceedings, pp. 1-12, 2009. 